\title{
ADAPTASI SPASIAL PADA RUMAH DOME NGELEPEN SUMBERHARJO, PRAMBANAN, SLEMAN
}

\author{
Priasmara Putra Marindrha \\ Program Studi S-2 Teknik Arsitektur Universitas Gadjah Mada \\ Email: priasmaraputram@mail.ugm.ac.id.
}

\begin{abstract}
The aim of this research is to know spatial adaptation of dome house of Ngelepen, Prambanan, Sleman, Yogyakarta which originally lived in Java traditional house, then moved to dome house which has different building characteristic in Java. The addition of outdoor space that occurred in Ngelepen dome provides an indication of the existence of the spatial adaptation of the living environment and human life. This research uses qualitative-rationalistic method approach. The results of this study led to the formation of spatial adaptation that occurred in the dome house Ngelepen is a functional adaptation to the needs of existing space. The adoption of functional adaptation by residents is the addition of outdoor space which includes the addition of new functions, the direction of adding new space, and the extent of the addition of function space. The social and economic aspects are the factors that influence the increase of space outside the dome house because of the change of status from the agrarian environment into the dome tourist village causing the increasing economic and social needs of the inhabitants.
\end{abstract}

Keywords: Functional, Ngelepen dome, Spatial adaptation, Space addition.

\begin{abstract}
ABSTRAK
Tujuan Kajian ini adalah untuk mengetahui adaptasi spasial rumah dome Ngelepen, Prambanan, Sleman, Yogyakarta yang semula tinggal di rumah adat Jawa, kemudian pindah ke rumah kubah yang memiliki karakteristik bangunan berbeda di pulau Jawa. Penambahan ruang luar yang terjadi di Ngelepen dome memberikan indikasi adaptasi spasial lingkungan dan kehidupan manusia. Kajian ini menggunakan pendekatan metode kualitatif-rasionalistik. Hasil Kajian ini menunjukkan bahwa bentuk adaptasi spasial yang terjadi di rumah dome Ngelepen merupakan adaptasi fungsional terhadap kebutuhan ruang yang ada. Penerapan adaptasi fungsional oleh penghuni adalah penambahan ruang di luar rumah yang meliputi penambahan fungsi baru, arah penambahan ruang baru, dan luasan penambahan fungsi ruang. Aspek sosial dan ekonomi adalah faktor-faktor yang mempengaruhi pertambahan ruang di luar rumah dome karena perubahan status dari lingkungan agraris ke desa wisata dome yang menyebabkan meningkatnya kebutuhan ekonomi dan sosial penghuni.
\end{abstract}

Kata kunci: Fungsional, Dome Ngelepen, Adaptasi spasial, Penambahan ruang.

\section{PENDAHULUAN}

Banyaknya bencana alam yang terjadi, seperti gempa bumi, angin kencang, kebakaran hutan, dan tsunami yang menghancurkan habitat manusia di seluruh dunia, menjadikan topik rekonstruksi hunian pasca bencana menjadi krusial dan penting. Penerapannya berdasarkan prinsip yang sama, yaitu efektif dan cepat tanggap, implementasinya fleksibel, dan kontekstual dengan potensi dan kondisi lokal setempat (McMullan, 2003; dalam Ikaputra, 2008). Saat ini implementasi tersebut berjalan melalui berbagai pendekatan langsung dengan korban bencana, mulai dari bantuan hunian sementara sampai rumah permanen. Rekonstruksi hunian pasca bencana dapat dilihat sebagai kesempatan untuk menciptakan kembali lingkungan binaan yang memenuhi semua kebutuhan masyarakat saat ini, melestarikan lingkungan alam dan memperhitungkan ancaman-ancaman yang akan datang (Yadav, 2014).

Sepuluh tahun lalu pada tanggal 27 Mei 2006, sebuah gempa bumi berkekuatan 5,9 skala Richter melanda Yogyakarta, membunuh lebih dari 5.000 jiwa. Lebih dari 10.000 rumah hancur dan 200.000 lainnya mengalami kerusakan. Ratusan ribu penduduk kehilangan rumah mereka. 
Hunian sementara sangat dibutuhkan para korban bencana, dan berbagai negara dan organisasi dunia turut menyediakan bantuan dalam bentuk makanan, obat medis, hunian sementara dan juga rumah. Sebuah organisasi amal dari Amerika Serikat, Domes for the World Foundation (DFTW) bekerja sama dengan World Association of Non-Governmental Organizations (WANGO) dan Muhammad Ali Alabbar, pemilik Dubai Emaar Property, Uni Emirat Arab mendonasikan 71 bangunan baru berupa Monolithic Ecoshell Dome bagi korban gempa di dusun Ngelepen sebagai rencana relokasi tempat tinggal mereka yang hancur terkena tanah longsor akibat gempa. Tujuannya adalah membuat suatu standar konstruksi prefabrikasi hunian pasca bencana yang aman dari gempa, bersifat permanen, ekonomis, dan efisien.

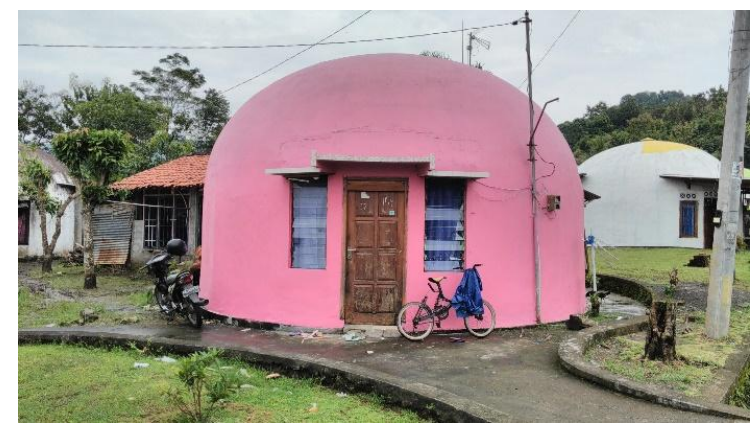

Gambar 1. Suasana rumah dome Ngelepen

Perkembangan dan perubahan rumah dome Ngelepen yang terjadi setelah dihuni terus dilakukan warga dalam memenuhi kebutuhan dan aktivitas sosial, ekonomi dan budaya. Rumah dome sebagai bagian rekonstruksi hunian pasca bencana telah menyediakan sarana bagi penghuni untuk memulihkan dan mengembangkan tempat tinggalnya sendiri dengan meningkatkan kegunaan dan nilai estetis dari sebuah hunian dan lingkungannya. Selama waktu tersebut, 46 rumah dome Ngelepen ditemukan mengalami penambahan fungsi ruang baru, diikuti arah penambahan ruangnya, dan luasan fungsi ruang baru dari penambahan tersebut. Ketiga perkembangan tersebut menandakan suatu bentuk penyesuaian ruang oleh penghuni terhadap lingkungannya yang baru. Penyesuaian antara individu dengan lingkungan ini, menurut Sarwono (1992:48), merupakan adaptasi. Menurut Sarwono kembali (1992:108-111), adaptasi adalah mengubah tingkah laku agar sesuai dengan lingkungan, sedangkan proses mengubah lingkungan agar sesuai tingkah laku dinamakan adjustment. Biasanya penghuni ruang mengadakan modifikasi spasial sesuai dengan kebutuhan untuk mendapatkan kepuasan yang lebih tinggi (Hester, 1975; Lang, 1974). Pengertian adaptasi dijelaskan oleh Holahan (1982) dan Soemarwoto (1991) merupakan proses, cara, perbuatan penyesuaian diri terhadap lingkungan, pekerjaan, dan pelajaran. Iskandar (2012: 46) menerangkan pengertian adaptasi sebagai suatu pergeseran kuantitatif dalam memberikan penilaian atau respon afeksi sepanjang stimulus yang menerpa dirinya secara terus-menerus. Beberapa pengertian tersebut dapat disimpulkan bahwa adaptasi adalah suatu proses perubahan berupa penyesuaian diri terhadap kondisi baru guna melangsungkan hidupnya.

Pengertian spasial menurut Kamus Lengkap Bahasa Indonesia (2006: 502) merupakan segala sesuatu yang berkenaan dengan ruang atau tempat. IImu arsitektur mengartikan spasial sebagai ruang interaksi manusia manusia dengan sesama dan lingkungan sekitarnya, baik disengaja maupun secara alamiah. Kata spasial berasal dari kata 'space' dalam arsitektur secara sederhana diartikan sebagai ruang, namun pengertian 'space' sendiri menurut para ahli mempunyai perbedaan sekaligus persamaan secara terminologinya, antara lain: 
a) Menurut Yi Fu Tuan (dalam Susanto, 2001:20), ruang merupakan sesuatu yang lebih abstrak dari sekedar tempat.

b) Leepel (dalam Susanto, 2001:20) menjelaskan ruang sebagai sesuatu yang di dalamnya manusia melakukan aktivitas, sesuatu yang mengijinkan terjadinya pergerakan sehingga pengertiannya tidak bisa dipisahkan dari pengalaman tempat.

c) Ruang menurut Nagy (dalam Susanto, 2001:8) merupakan hubungan antara posisi wadahwadah, batas-batasnya menjadi cair, dimengerti sebagai aliran suksesi hubungan-hubungan yang tak terhitung jumlahnya.

d) Menurut Schulz (1984:11), ada dua pengertian mengenai ruang, yaitu sebagai geometri tiga dimensional dan sebagai bidang persepsual.

e) Pengertian ruang menurut Paolo Potoghesi (dalam Schulz, 1984:11) adalah sebuah sistem tempat.

f) Trancik (1986:61) berpendapat ruang di dalam skala kota terbagi menjadi dua tipe, yaitu hard space dan soft space. Hard space secara prinsip merupakan ruang yang dibatasi oleh dinding arsitektural dengan maksud sebagai tempat pertemuan besar untuk beraktivitas sosial. Soft space didominasi oleh lingkungan alam, baik yang di dalam maupun di luar kota.

g) Peterson (1986:61) menerangkan ruang menjadi dua pengertian, yaitu space dan anti-space. Space merupakan sesuatu yang dipikirkan atau terkonsep, terukur yang memiliki batas-batas, secara prinsip tidak bersambung, tertutup, statis, belum berupa rangkaian dalam suatu komposisi, semisal plaza. Antispace tak berbentuk, bersambung, bentuk dan batas pinggirnya tidak penuh, seperti menara yang ada di dalam taman.

Berdasarkan uraian-uraian di atas, secara sederhana dapat ditarik kesimpulan bahwa ruang atau spasial bukan hanya dibatasi oleh batasan-batasan yang berwujud fisik semata secara geometri atau tiga dimensi, namun juga dapat dibatasi oleh batas persepsi manusia sendiri.

Istilah adaptasi spasial berdasarkan penjelasan-penjelasan sebelumnya dapat diartikan sebagai suatu proses penyesuaian diri terhadap kondisi ruang atau tempat baru. Proses penyesuaian tersebut merupakan hubungan antara perilaku manusia dengan pengaturan fisik di ruang baru yang mencakup aktivitas manusia. Berbagai macam aktivitas menciptakan fungsi ruang yang beragam pula. Penggunaan ruang dapat berubah secara fleksibel sesuai dengan banyaknya kebutuhan yang harus dipenuhi.

Proses adaptasi spasial manusia juga berhubungan dengan fleksibilitas tempat manusia berada. Proses tersebut dapat berjalan tergantung sifat adaptif pelaku terhadap lingkungan fisik baru atau pengaturan lingkungan fisik baru yang disesuaikan dengan keinginan pelaku. Holahan dalam Hadinugroho (2002: 7) mengemukakan tiga hal yang mempengaruhi adaptasi manusia, antara lain:

1. Environmental Perception, yaitu proses memahami lingkungan fisik melalui input indrawi dari stimuli yang baru saja terjadi.

2. Environmental Cognition, yaitu proses menyimpan, mengorganisasikan, mengkonstruksi, dan memanggil kembali imaji, ciri-ciri, atau kondisi 
lingkungan yang sudah ada atau terjadi beberapa saat yang lalu.

3. Environmental Attitudes, yaitu rasa suka atau tidak terhadap sifat atau ciri kondisi lingkungan fisiknya.

Adaptasi manusia terhadap tempat tinggalnya meliputi dua cara, yaitu adaptasi cara aktif dan cara pasif (Afandi, 2017). Adaptasi cara aktif merupakan adaptasi dengan berusaha menyiasati kondisi yang ada di tempat tinggalnya, misal mengubah lingkungan atau hunian sesuai keinginan dan selera penghuni. Adaptasi cara pasif adalah adaptasi dengan menerima kondisi yang ada dan menyesuaikan diri dengan lingkungan atau hunian yang baru. Permasalahan akan selalu muncul karena perubahanperubahan yang terus dilakukan, baik penghuni terhadap habitatnya maupun sebaliknya. Perubahan tersebut juga merupakan bentuk stimulus dalam mendapatkan kenyamanan dan kepuasan diri. Jika tidak melakukan perubahan tersebut, dampaknya dapat menimbulkan stres dan mengganggu kondisi psikologis penghuni. Perubahan-perubahan yang terjadi juga disesuaikan dengan kondisi penghuninya. Tentunya menarik untuk melihat bagaimana bentuk adaptasi spasial tiap rumah dome Ngelepen dan faktor-faktor yang mempengaruhinya setelah 10 tahun dihuni berbeda-beda tergantung kebutuhan masing-masing penghuni.

\section{METODE}

Kajian ini dilakukan atas dasar menjawab pertanyaan Kajian untuk mengungkap suatu fenomena sosial atau alami tertentu (Singarimbun, 1995). Selain itu, Kajian ini dilakukan karena juga banyak berhubungan dengan hal-hal yang memiliki realitas ganda yang dirasakan dan sangat dipercaya oleh masyarakat setempat tetapi sulit untuk dijelaskan keberadaannya. Sesuai dengan karakteristik objek studi (masalah dan persoalan pokok Kajian), maka paradigma yang dipakai dalam Kajian ini adalah kualitatif-rasionalistik.

Lokasi kajian berada pada kawasan rumah dome di dusun Ngelepen, Sumberharjo, Prambanan, Sleman, Daerah Istimewa Yogyakarta. Objek Kajian ini berupa rumah relokasi dari korban gempa Yogyakarta yang terjadi pada tanggal 27 Mei 2006. Luas tapak komplek dome Ngelepen berukuran dua hektar yang terdiri dari 71 rumah dome dan 4 sarana pendukung seperti masjid, Taman Kanak-kanak (TK), MCK bersama (Mandi, Cuci, Kakus) dan puskesmas. Berdasarkan data kependudukan, mayoritas mata pencaharian penduduknya bertsatus petani dan buruh, sisanya sebagai wirausahawan dan pegawai negeri. Status bangunan sudah menjadi hak milik dan hak pakai sejak terbangunnya rumah dome, namun untuk status tanah masih sewa ke pemerintah desa Sumberharjo. Keseluruhan 71 rumah dome yang terbangun hanya 54 dihuni warga. Sisa 17 rumah yang kosong dijadikan homestay.

Objek amatan yang akan diteliti bersifat homogen. Seluruh rumah dome merupakan bangunan prefabrikasi dan hunian pasca bencana, dimana 17 rumah tidak terhuni yang difungsikan sebagai homestay dengan pengelolaan swadaya warga Ngelepen sendiri yang berasal dari dana pemasukan objek desa wisata bencana gempa rumah "teletubbies" New Ngelepen, dan 54 rumah terhuni. Sejumlah 46 rumah dome mengalami penambahan ruang, sisanya dalam kondisi tetap atau tak mengalami 
penambahan ruang. Variabel Kajian ini merujuk pada referensi pada tinjauan pustaka yang membahas mengenai adaptasi spasial. Variabel-variabel yang akan diamati dalam Kajian ini dibagi menjadi dua aspek, yaitu aspek arsitektur dan aspek non-arsitektural.

Sampel merupakan sejumlah bagian objek amatan yang diambil dari populasi sesuai prosedur tertentu, sehingga dapat merepresentasi keseluruhan populasi dalam suatu pengamatan. Pendekatan kualitatif-rasionalistik tidak memberikan arahan tertentu mengenai jumlah sampel yang perlu diambil. Prinsipnya, setiap sampel yang diambil cukup mewakili populasi yang ada dalam menjawab rumusan masalah Kajian. Penentuan sampel yang dilakukan menggunakan metode purposive-sampling dengan mengambil subjek tidak berdasarkan strata, random atau daerah, namun berdasarkan dari tujuan tertentu. Peneliti menentukan sampel pada saat melakukan Kajian di lapangan. Berikut kriteria pemilihan sampel rumah dome Ngelepen:

1. Rumah dome yang mengalami pengembangan ruang.

2. Rumah dome yang terhuni pada saat dilakukan Kajian dan masih berfungsi sebagai rumah tinggal.

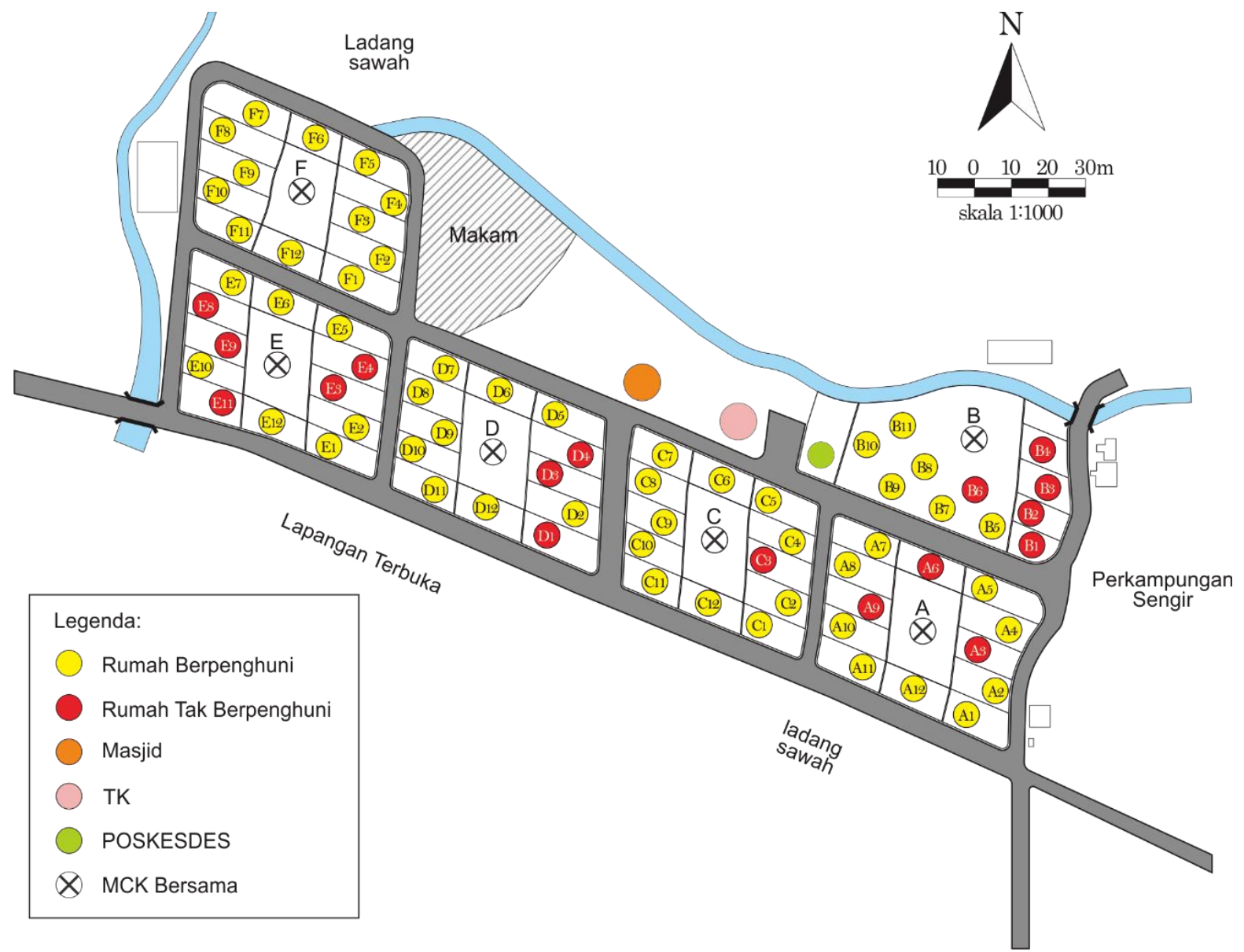

Gambar 2. Peta Skematik Komplek Rumah dome Ngelepen 
Tabel 1. Variabel Kajian

\begin{tabular}{|c|c|c|}
\hline Variabel & Elemen yang diteliti & Keterangan \\
\hline Bentuk Bangunan & $\begin{array}{l}\text { Bentuk Bangunan } \\
\text { - Fungsi ruang baru } \\
\text { - Arah penambahan ruang } \\
\text { - Dimensi ruang }\end{array}$ & $\begin{array}{l}\text { Mengamati penambahan atau } \\
\text { tidak keadaan fisik rumah yang } \\
\text { terjadi selama dihuni seiring } \\
\text { perkembangan kebutuhan } \\
\text { hidup yang perlu dipenuhi } \\
\text { warga. }\end{array}$ \\
\hline $\begin{array}{l}\text { Pengaruh pengembangan } \\
\text { rumah terkait dengan aspek } \\
\text { sosial, ekonomi, dan budaya. }\end{array}$ & $\begin{array}{l}\text { a) Ekonomi } \\
\text { - Bertambahnya jumlah keluarga. } \\
\text { - Mata pencaharian. } \\
\text { - Pendapatan keluarga. } \\
\text { b) Sosial } \\
\text { c Status sosial dalam keluarga. } \\
\text { c) Budaya } \\
\text { - Penambahan ornamen karena tradisi. }\end{array}$ & $\begin{array}{lr}\text { Mengamati perkembangan } \\
\text { pada setiap } & \text { elemen } \\
\text { berdasarkan faktor } & \text { ekonomi, } \\
\text { sosial dan budaya. }\end{array}$ \\
\hline
\end{tabular}

\section{HASIL DAN PEMBAHASAN}

Desain awal rumah dome Ngelepen merupakan hunian dengan diameter berukuran 7,3 meter dan luas bangunan $38,5 \mathrm{~m}^{2}$ yang terbagi dua lantai, antara lain: lantai pertama yang meliputi fungsi ruang tamu, dua kamar tidur, dan dapur; dan lantai kedua yang meliputi fungsi ruang keluarga.

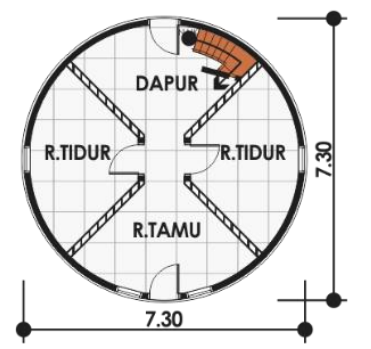

Lantai 1

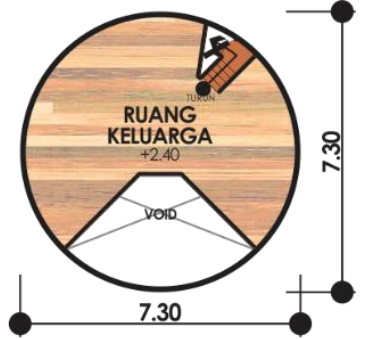

Lantai 2
Gambar 3. Denah awal dome Ngelepen

Pada saat ini, rumah dome mengalami perkembangan berupa penambahan ruang di luar rumah dome itu sendiri. Penambahan ruang di luar rumah dome dilakukan penghuni dalam merespon kebutuhan sehari-hari terhadap kondisi dome yang ada. Jumlah 71 rumah dome yang ada, peneliti menemukan terdapat sejumlah 46 rumah yang melakukan penambahan ruang tersebut. Dari temuan tersebut, peneliti menemukan adanya tiga aktivitas penambahan yang dilakukan oleh penghuni, yaitu a) penambahan fungsi ruang baru, b) arah penambahan fungsi ruang, dan c) penambahan luasan ruang. Ketiga aktivitas tersebut dapat diterjemahkan sebagai suatu bentuk penyesuaian atau adaptasi spasial terhadap kondisi dome yang ada. Berikut pembahasan ketiga aktivitas tersebut:

1. Penambahan fungsi ruang baru Adaptasi ruang secara fungsional ini merupakan upaya penghuni dalam memenuhi kebutuhan dan kegiatan sehari-hari. Adaptasi ini sebagai bentuk penyesuaian penghuni terhadap tata ruang dome yang ada. Jenis-jenis tambahan ruang yang ditemui di lapangan berjumlah dua belas ruang, yaitu: dapur, ruang jualan, kandang, teras, kamar mandi, kamar tidur, gudang, garasi, tempat cuci, tempat jemur, ruang bersama, dan ruang tidur. 


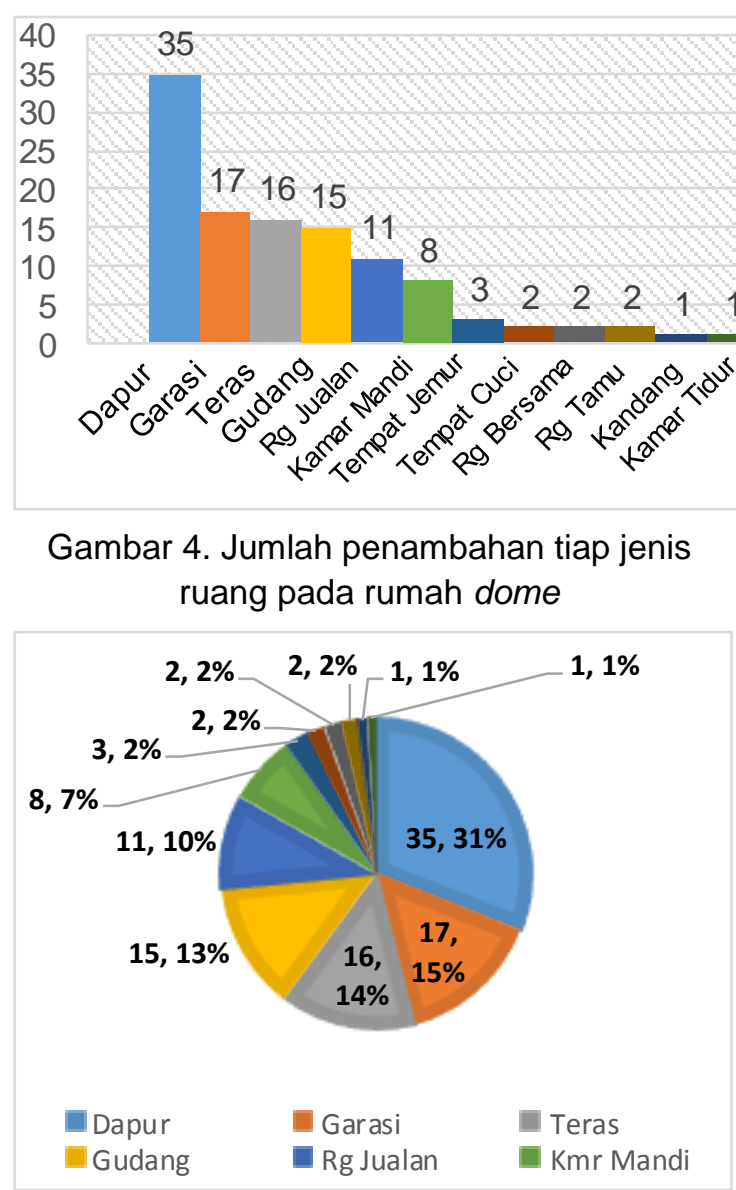

Gambar 5. Persentase penambahan jenis ruang pada rumah dome

Gambar grafik di atas menunjukkan bahwa dapur menjadi ruang yang paling dominan dalam penambahan jenis ruang dengan mendapatkan jumlah total 35 ruang (31\%), kemudian garasi sejumlah 17 ruang (15\%), lalu teras dan gudang mendapatkan jumlah ruang sebanyak 16 ruang (14\%) dan 15 ruang (13\%). Beberapa jenis ruang lainnya adalah ruang jualan sejumlah 11 ruang $(10 \%$,) dan kamar mandi sejumlah 8 ruang $(7 \%)$. Jenis ruang yang paling sedikit jumlahnya adalah ruang kandang dan kamar tidur masing-masing sebanyak 1 ruang $(1 \%)$, selanjutnya tempat cuci, ruang bersama, dan ruang tamu masing-masing mendapatkan jumlah total sebanyak 2 ruang (2\%). Terakhir tempat jemur mendapatkan jumlah 3 ruang (2\%).
2. Arah penambahan fungsi ruang Adaptasi arah penambahan ruang merupakan adaptasi terhadap bentuk dome sehingga terjadi arah penambahan ruang di luar dome dari berbagai sisi.

Tabel 2. Jumlah total arah penambahan ruang

\begin{tabular}{clcc}
\hline No. & Penambahan Ruang & Jumlah & Persentase \\
\hline 1 & Belakang & 29 & $41 \%$ \\
2 & Tetap & 25 & $35 \%$ \\
3 & Depan-Belakang & 12 & $17 \%$ \\
4 & Depan & 3 & $4 \%$ \\
5 & Belakang-Samping & 2 & $3 \%$ \\
\hline \multicolumn{2}{c}{ TOTAL } & 71 & $100 \%$ \\
\hline
\end{tabular}

Total terdapat 4 kategori penambahan fungsi ruang yang ditemui berdasarkan arah penambahan ruangnya, yaitu di belakang, depan, depan-belakang, dan belakang-samping.

Tabel 3. Penambahan ruang di belakang dome

\begin{tabular}{|c|c|c|c|}
\hline No. & $\begin{array}{l}\text { Penambahan Fungsi Ruang } \\
\text { di Belakang Dome }\end{array}$ & $\begin{array}{l}\text { Jumlah } \\
\text { Rumah }\end{array}$ & $\begin{array}{c}\text { Besar } \\
\text { Persentase }\end{array}$ \\
\hline 1 & Dapur & 9 & $13 \%$ \\
\hline 2 & Dapur + Gudang + Garasi & 3 & $4 \%$ \\
\hline 3 & Dapur + Garasi & 2 & $3 \%$ \\
\hline 4 & Dapur + Gudang & 2 & $3 \%$ \\
\hline 5 & Kamar Mandi & 1 & $1 \%$ \\
\hline 6 & Dapur + Teras & 1 & $1 \%$ \\
\hline 7 & Teras + Kamar Mandi & 1 & $1 \%$ \\
\hline 8 & Garasi + Tempat Jemur & 1 & $1 \%$ \\
\hline 9 & $\begin{array}{l}\text { Dapur + Rg. Jualan + } \\
\text { Teras }\end{array}$ & 1 & $1 \%$ \\
\hline 10 & Dapur + Kamar Mandi & 1 & $1 \%$ \\
\hline 11 & Dapur + Gudang + Teras & 1 & $1 \%$ \\
\hline 12 & $\begin{array}{l}\text { Dapur + Gudang + Kamar } \\
\text { Mandi }\end{array}$ & 1 & $1 \%$ \\
\hline 13 & $\begin{array}{l}\text { Dapur + Gudang + } \\
\text { Kandang }\end{array}$ & 1 & $1 \%$ \\
\hline 14 & $\begin{array}{l}\text { Dapur + Garasi + Kamar } \\
\text { Mandi }\end{array}$ & 1 & $1 \%$ \\
\hline 15 & $\begin{array}{l}\text { Garasi + Tempat Cuci + } \\
\text { Kamar Mandi }\end{array}$ & 1 & $1 \%$ \\
\hline 16 & $\begin{array}{l}\text { Dapur + Gudang + Garasi } \\
+ \text { Teras }\end{array}$ & 1 & $1 \%$ \\
\hline 17 & $\begin{array}{l}\text { Dapur + Teras + Gudang } \\
+ \text { Kamar Mandi + Rg. }\end{array}$ & 1 & $1 \%$ \\
\hline
\end{tabular}




\begin{tabular}{ccc}
\hline No. $\begin{array}{l}\text { Penambahan Fungsi Ruang } \\
\text { di Belakang Dome }\end{array}$ & $\begin{array}{l}\text { Jumlah } \\
\text { Rumah }\end{array}$ & $\begin{array}{c}\text { Besar } \\
\text { Persentase }\end{array}$ \\
\hline Tamu & & \\
\hline TOTAL & 29 & $41 \%$ \\
\hline
\end{tabular}

Tabel 4. Penambahan ruang di depan dome

\begin{tabular}{clcc}
\hline No. & $\begin{array}{l}\text { Penambahan Fungsi Ruang } \\
\text { di depan Dome }\end{array}$ & $\begin{array}{c}\text { Jumlah } \\
\text { Rumah }\end{array}$ & $\begin{array}{c}\text { Besar } \\
\text { Persentase }\end{array}$ \\
\hline 1 & Rg. Jualan & 1 & $2 \%$ \\
2 & Teras + Garasi & 1 & $1 \%$ \\
3 & Teras + Garasi + Gudang & 1 & $1 \%$ \\
\hline & TOTAL & 3 & $4 \%$ \\
\hline
\end{tabular}

Tabel 5. Penambahan ruang di depan-belakang dome

\begin{tabular}{|c|c|c|c|}
\hline No. & $\begin{array}{l}\text { Penambahan Fungsi Ruang } \\
\text { di Depan-Belakang Dome }\end{array}$ & $\begin{array}{l}\text { Jumlah } \\
\text { Rumah }\end{array}$ & $\begin{array}{c}\text { Besar } \\
\text { Persentase }\end{array}$ \\
\hline 1 & Dapur + Rg. Jualan & 2 & $3 \%$ \\
\hline 2 & Dapur + Teras & 1 & $2 \%$ \\
\hline 3 & Garasi + Rg. Bersama & 1 & $2 \%$ \\
\hline 4 & $\begin{array}{l}\text { Tempat Jemur + Rg. } \\
\text { Jualan }\end{array}$ & 1 & $2 \%$ \\
\hline 5 & Dapur + Teras + Garasi & 1 & $2 \%$ \\
\hline 6 & Dapur + Gudang + Teras & 1 & $1 \%$ \\
\hline 7 & $\begin{array}{l}\text { Dapur + Gudang + Teras } \\
+ \text { Rg. Jualan }\end{array}$ & 1 & $1 \%$ \\
\hline 8 & $\begin{array}{l}\text { Dapur + Kamar Mandi + } \\
\text { Garasi + Rg. Tamu }\end{array}$ & 1 & $1 \%$ \\
\hline 9 & $\begin{array}{l}\text { Tempat Cuci + Tempat } \\
\text { Jemur + Garasi + Rg. } \\
\text { Jualan + Teras }\end{array}$ & 1 & $1 \%$ \\
\hline 10 & $\begin{array}{l}\text { Dapur + Kamar Tidur }+2 \\
\text { Rg. Jualan }+2 \text { Teras }\end{array}$ & 1 & $1 \%$ \\
\hline 11 & $\begin{array}{l}\text { Dapur + Garasi + } 2 \text { Rg. } \\
\text { Jualan + Gudang + Teras }\end{array}$ & 1 & $1 \%$ \\
\hline & TOTAL & 12 & $17 \%$ \\
\hline
\end{tabular}

Tabel 6. Penambahan ruang di belakangsamping dome

\begin{tabular}{cccc}
\hline No. & $\begin{array}{c}\text { Penambahan Fungsi Ruang } \\
\text { di Belakang-Samping Dome }\end{array}$ & $\begin{array}{c}\text { Jumlah } \\
\text { Rumah }\end{array}$ & $\begin{array}{c}\text { Besar } \\
\text { Persentase }\end{array}$ \\
\hline 1 & Gudang + Garasi & 1 & $2 \%$ \\
2 & Dapur + Rg. Bersama & 1 & $1 \%$ \\
\hline \multirow{2}{*}{ TOTAL } & 2 & $3 \%$ \\
\hline
\end{tabular}

Pada tabel-tabel tipe penambahan fungsi ruang berdasarkan arah penambahannya di atas, dapat diketahui bahwa arah penambahan ruang di belakang dome menjadi yang paling banyak menghasilkan tipe ruang sebanyak 17 tipe fungsi ruang dengan dapur sebagai fungsi ruang yang paling banyak ditemui sejumlah 9 rumah atau sebanyak $13 \%$.

3. Penambahan luasan ruang

Adaptasi ini merupakan adaptasi luasan dengan kebutuhan fungsi penghuni dome terhadap arah pengembangan ruang sesuai luasan tapak yang dimiliki. Luasan pada tiap penambahan ruang berbeda-beda tiap dome sesuai dengan kebutuhan dan arah pengembangannya. Hasil yang ada di lapangan ditemukan bahwa ada 6 tipe penambahan luasan ruang yang terjadi pada dome Ngelepen, yaitu luasan dengan penambahan 1 ruang, 2 ruang, 3 ruang, 4 ruang, 5 ruang, dan 6 ruang.

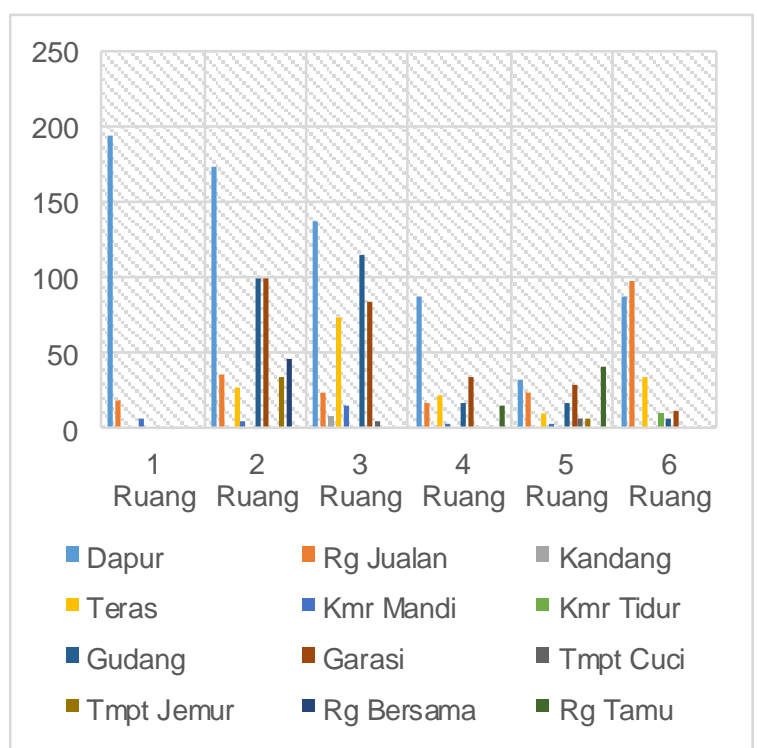

Gambar 6. Grafik jumlah besaran dimensi tambahan ruang pada rumah dome 


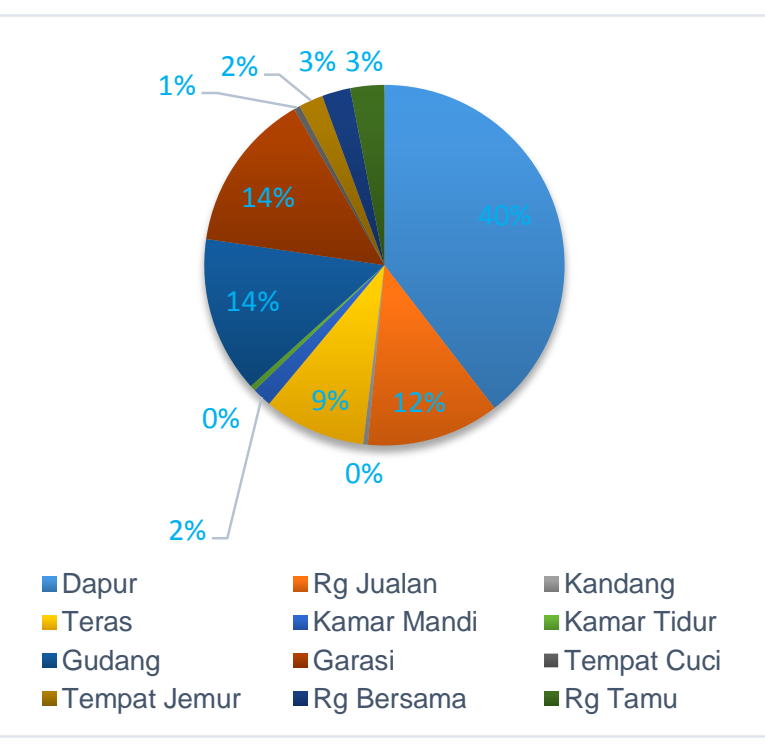

Gambar 7. Grafik persentase besaran dimensi ruang pada rumah dome

Pada besaran dimensi ruang seperti yang terlihat pada grafik di atas. menunjukkan bahwa dapur menjadi ruang yang paling besar dalam jumlah total besaran dimensi ruang, yaitu sebesar $712,5 \mathrm{~m}^{2}$, kemudian pada gambar grafik di atas, dapur menjadi ruang dengan besaran dimensi yang paling dominan pada beberapa tambahan ruang antara lain tambahan 1 jenis ruang, 2 jenis ruang, 3 jenis ruang, dan 4 jenis ruang. Grafik selanjutnya juga memperlihatkan dapur sebagai besaran dimensi jenis ruang dengan tingkat persentase yang paling tinggi, yaitu sebanyak $40 \%$. Jenis ruang lain berikutnya dengan selisih jumlah total besaran ruang yang hampir berdekatan, yaitu garasi $\left(258 \mathrm{~m}^{2}\right)$, gudang $\left(252,75 \mathrm{~m}^{2}\right)$, ruang jualan $\left(215 \mathrm{~m}^{2}\right)$, dan teras $\left(165 \mathrm{~m}^{2}\right)$. Ruang tamu menjadi ruang paling dominan jumlah besaran dimensinya dibandingkan ruang lainnya pada tambahan 5 jenis ruang, sedangkan ruang jualan menjadi jenis ruang yang paling dominan dibandingkan dengan ruang dapur pada jumlah besaran dimensi tambahan 6 jenis ruang pada rumah dome. Tingkat persentase pada ruang-ruang tersebut juga berselisih sedikit, antara lain: garasi dan gudang masing-masing dengan persentase
$14 \%$, ruang jualan sebanyak $12 \%$, dan teras sebanyak $9 \%$. Jumlah besaran dimensi ruang berikutnya adalah jenis ruang dengan besaran ruang yang kecil, antara lain: ruang tamu, ruang bersama, tempat jemur, tempat cuci, kamar tidur, dan kandang. Grafik persentase besaran dimensi jenis ruang memperlihatkan bahwa jenis ruang tersebut memiliki tingkat persentase paling sedikit dibandingkan dengan jenis ruang lainnya, antara lain: kamar tidur dan kandang mendapatkan persentase sebanyak $0 \%$, tempat cuci sebanyak $1 \%$, tempat jemur sebanyak $2 \%$, dan ruang bersama dan ruang tamu masing-masing mendapatkan 3\%.

\section{SIMPULAN}

Rumah dome Ngelepen merupakan hunian permanen yang digagas oleh organisasi amal dunia bersama dengan pemerintah daerah, institusi pendidikan, dan masyarakat setempat untuk memenuhi kebutuhan masyarakat korban longsor akibat gempa bumi agar mendapatkan hunian yang layak dan aman dari dampak bencana alam. Pada dasarnya terdapat beberapa perubahan dan penyesuaian yang dilakukan masyarakat dusun Sengir dalam merespon rumah tinggal mereka yang berbeda dengan rumah pada umumnya. Berdasarkan pengamatan terhadap beberapa kasus rumah bisa disimpulkan bahwa telah terjadi adaptasi spasial penghuni terhadap rumah dome yang dapat dilihat melalui rincian berikut ini: 1) Bentuk adaptasi spasial yang terjadi di rumah dome Ngelepen adalah adaptasi secara fungsional terhadap kebutuhan ruang yang ada. Penerapan dari adaptasi secara fungsional yang dilakukan penghuni berupa penambahan ruang di luar rumah yang meliputi penambahan fungsi baru, arah penambahan ruang baru, dan luasan penambahan fungsi ruang. Dominasi dapur 
sebagai penambahan fungsi ruang yang paling banyak terjadi dipengaruhi oleh faktor masih besarnya kebutuhan layanan rumah tangga, meskipun pada rumah dome sendiri sudah terdapat dapur. Hal ini terjadi karena konsep ruang dapur dalam rumah adat masyarakat Jawa adalah dapur kotor. Dapur yang ada di dome diibaratkan sebagai dapur bersih. Arah penambahan ruang di luar rumah dome yang sering terjadi berada di bagian belakang; dan bagian belakang-depan rumah. Kebutuhan akan ruang privasi dan ruang untuk berkegiatan ekonomi serta sosial menjadi peran berkembangnya arah penambahan ruang baru di luar rumah dome. Tambahan fungsi baru di luar dome juga berdampak pada bertambahnya luasan atau besaran ruang dari kondisi ruang yang ada. Dapur menjadi luasan ruang dengan pertambahan yang cukup signifikan; 2) Aspek sosial dan ekonomi menjadi faktor yang mempengaruhi pertambahan ruang di luar rumah dome karena perubahan status dari lingkungan agraris menjadi desa wisata dome yang menyebabkan meningkatnya kebutuhan ekonomi dan sosial penghuni. Kegiatan pariwisata membantu penghuni dalam mengelola komplek rumah dome secara swadaya terutama status tanah masih milik pemerintah daerah sehingga adaptasi spasial yang dilakukan penghuni disesuaikan dengan perkembangan pariwisata yang ada.

\section{DAFTAR RUJUKAN}

Bintari, Bertha. 2012. Rumah Dome New Ngelepen Yogyakarta: Bukan Sebuah Pendekatan Perancangan yang Berempati. Dies 45 Jurusan Arsitektur Universitas Kristen Petra, Seminar Nasional - Menuju Arsitektur berEmpati, Surabaya.
Desiyana, Irma. 2008. Dome Bagi Korban Gempa di Ngelepen, Yogyakarta: Suatu Kajian Terhadap Ketahanan Berhuni Dalam Rumah Hasil Bantuan Pasca Bencana. Skripsi Jurusan Arsitektur, Universitas Indonesia.

Hartiningsih. 2008. Perubahan Sistem Spasial Rumah Tinggal Berfungsi Ganda di Daerah Umbulharjo, Yogyakarta. Lintas Ruang Vol. 2 Edisi 2.

Hester, Randolph T. 1975. Neighborhood Space . Stroudsburg: Dowden, Hudchinson \& Ross.

Ikaputra, 2008. People Response to Localize Imported Culture; Study Case: The Dome House in The Rural Culture Post Javanese Earthquake 2006. The 14th World Conference on Earthquake Engineering, Beijing, China.

Lang, Jon. 1974. Designing for Human Behavior, Architecture and The Behavioral Sciences. Stroudsburg: Dowden, Hudchinson \& Ross.

Lang, Jon. 1987. Creating Architectural Theory. The Role of the Behavioral Sciences in Environmental Design, NEW YORK: Van Nostrand Reinhold Company.

Nugroho, Martino Dwi. 2008. Adapatasi Spasial Pada Interior Rumah Tinggal Pasca Gempa di Kasongan, Bantul. Lintas Ruang Vol. 2 Edisi 3.

Marcilia, Syam Rachma \& Ohno, Ryuzo. 2012. Residents' Usage of, Adjustment to, And Evaluation of Donated Post-Disaster Housing. Vulnerability, Risks, and Complexity: Impacts of Global Change on Human Habitats. Hogrefe Publishing.

Michelson, Williams, Robert B, Robert W. 1986. Methods in Enviromental and Behavioral Research. New York: Van Nostarnd Reinhold Co.

Pratama, Dandi Raviandaru. 2016. Pola Perubahan Desain Rumah Dome Pasca 
Bencana Gempa di Prambanan, Sleman, Yogyakarta. Malang: Skripsi S-1 Teknik Arsitektur Universitas Brawijaya.

Purwanto AN, 2003. Studi Perubahan Spasial Rumah Tinggal Menjadi Rumah Pondokan Mahasiswa Di Yogyakarta. Yogyakarta: Tesis S2 Jurusan Arsitektur UGM.

Rusydi, Mohammad. 2008. Perilaku Penghuni Rumah Dome di Prambanan, Sleman: Adaptasi dan Adjustment di Setting Baru, Lintas Ruang Vol. 2 edisi 3.

Saraswati, Titien, 2007. Kontroversi Rumah Dome di Ngelepen, Prambanan, D.I .Yogyakarta, Jurnal Dimensi Desember.

Suryandono, Alexander \& Wong, Peter. 2012. Locally Based Approach for Prefabricated Housing; Case Study: Indonesia. ACSA Fall Conference, Philadelphia, USA. 